\title{
Quiz-Based Microlearning at Scale: a Rapid Educational Response to COVID-19
}

\author{
Austin J. Triana ${ }^{1}$ (D) Colin G. White-Dzuro ${ }^{1}$ Jonathan Siktberg ${ }^{1} \cdot$ Benjamin D. Fowler $^{1,2} \cdot$ Bonnie Miller $^{3}$
}

Accepted: 14 September 2021 / Published online: 23 September 2021

(c) International Association of Medical Science Educators 2021

\begin{abstract}
Virtual quizzing is a viable model for continuing education at a large scale, particularly during the COVID-19 pandemic. By leveraging technology, microlearning encourages mobile education that is engaging, flexible, and accessible. Learners reported that this format was effective and preferable to traditional methods of education, suggesting further opportunity for innovation.
\end{abstract}

Keywords Virtual $\cdot$ Quizzing $\cdot$ Microlearning $\cdot$ Continuing education $\cdot$ Scalable

\section{Main Text}

The COVID-19 pandemic challenged the field of continuing education (CE) for health professionals in several ways. First, it created a need to rapidly distribute high-quality education about the evolving pandemic to large numbers of providers. Second, many traditional CE offerings were canceled because of public health restrictions. These obstacles presented an opportunity for innovation with emerging educational approaches, which could prove superior to the passive didactic formats that persist in CE despite growing evidence of their ineffectiveness [1]. Test-enhanced learning (TEL) and microlearning are two such emerging approaches. TEL has been previously shown to promote long-term knowledge retention in medical education settings, and microlearning is a form of spaced learning in which information is split into small units that are delivered over a short period of time [2].

QuizTime is a web-based platform developed by the Vanderbilt University Medical Center (VUMC) that delivers learning activities based on the principles of TEL and microlearning. To meet the needs of practicing providers,

Austin J. Triana

austin.j.triana@vanderbilt.edu

1 School of Medicine, Vanderbilt University, Nashville, TN, USA

2 Department of Pathology, Microbiology and Immunology, Vanderbilt University Medical Center, Nashville, TN, USA

3 Office of Health Sciences Education, Vanderbilt University, Nashville, TN, USA this study used virtual quiz-based microlearning to deliver CE that is interactive, adaptable, convenient, and relevant to the current pandemic. The QuizTime platform delivers one multiple-choice quiz question each weekday by email or text to enrolled learners at a time designated by the learner. Each learner receives a link to a quiz item that includes a clinical scenario, a question, and four possible answers. After learners answer the question, the platform provides the correct response and a concise summary of major concepts.

The fifteen-question "Conquering COVID" quiz launched on April 13, 2020, spanning basic science, epidemiology, management, and treatment. The quiz was promoted via a twice-weekly newsletter, sent electronically to all employees in the medical center and medical students in a required course about the pandemic. After the quiz, eligible learners were able to claim three AMA PRA Category 1 credits if they engaged with at least $80 \%$ of the quiz items. In addition, a seven question, five-point Likert scale feedback survey was sent to the users to assess their experiences with the quiz and the learning platform.

The quiz was completed by 805 of the 1,132 enrollees $(71.1 \%)$. The learner population consisted of physicians $(28.0 \%)$, nurses $(22.0 \%)$, nurse practitioners $(14.9 \%)$, allied health professionals $(11.3 \%)$, and other learners. The most commonly represented specialties were medicine (14\%), pediatrics (11.7\%), and family medicine (10.1\%). Learners responded correctly on $49.4 \%$ of first attempts and $87.3 \%$ of second attempts.

Survey results were overwhelmingly positive (Fig. 1). A large majority of respondents were satisfied or very 
A
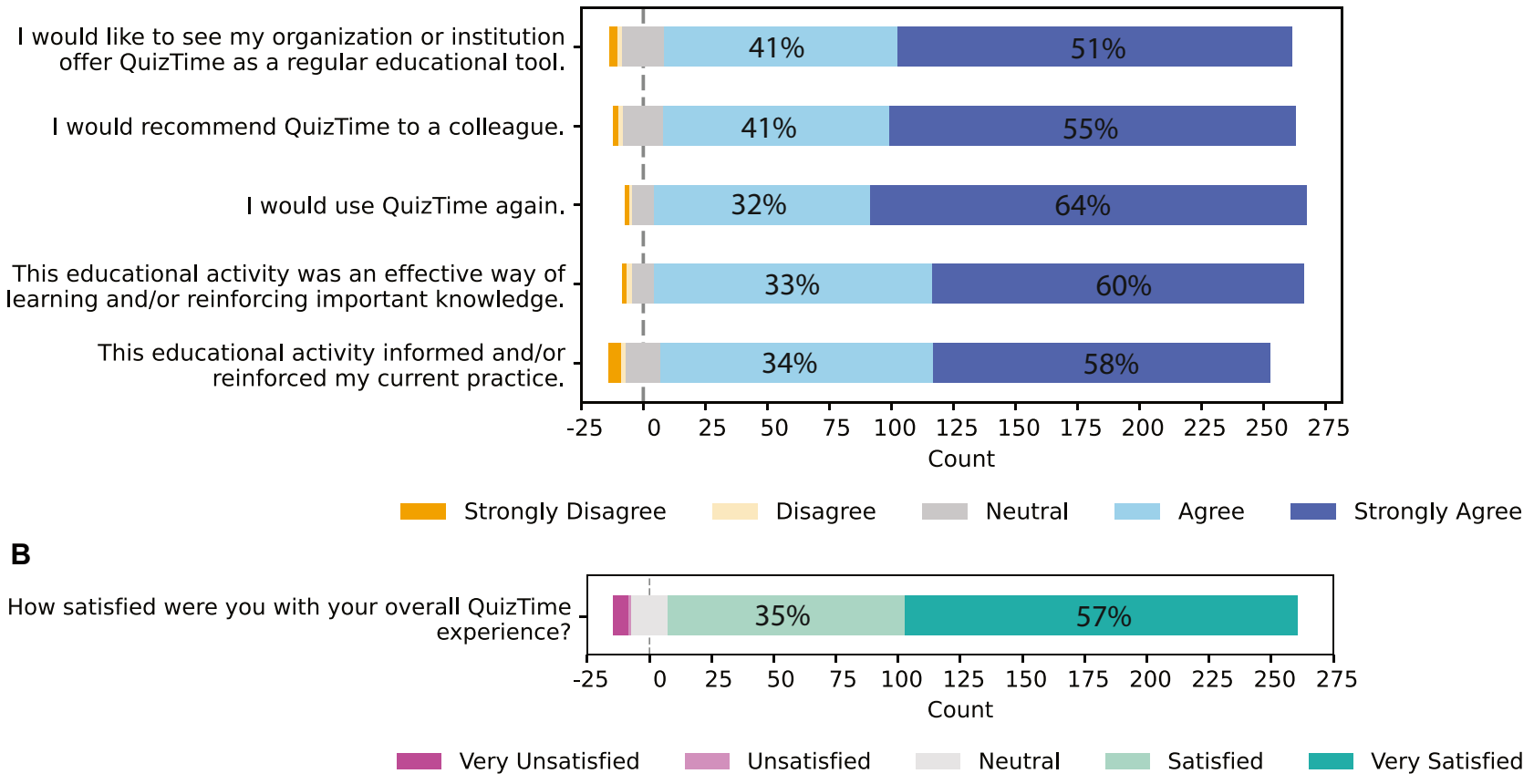

C

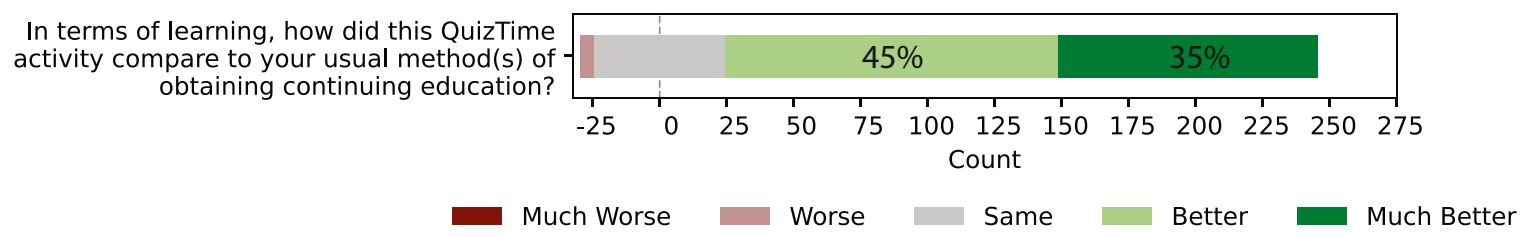

Fig. 1 Survey results of learner perceptions of QuizTime's "Conquering COVID.” N=275. Survey questions were scored on a five-point Likert scale shown above

satisfied with the overall QuizTime experience (91.6\%). Most respondents agreed or strongly agreed that the activity informed and/or reinforced practice habits (89.5\%), and a majority reported that QuizTime was either better or much better than their usual learning methods $(80.4 \%)$.

This work demonstrated that virtual quiz-based microlearning is feasible and scalable, and it is preferred by a majority of learners when compared to traditional methods of continuing education. Because smartphones are nearly ubiquitous, this model leverages technology by engaging learners at their convenience. The QuizTime activity also met the challenge of rapid production and distribution. "Conquering COVID" was developed in three weeks and was completed by the first enrollees in another three weeks, a testament to its speed, relevance, and responsiveness.

Additionally, evidence from cognitive science supports the QuizTime approach. Recalling previously learned information enhances the ability to remember that information in the future; by responding to quiz items and receiving feedback, the cognitive imprint is strengthened, and retention is improved. By delivering only one question per day, quiz-based microlearning also takes advantage of the spacing effect, the finding that learning becomes more effective when it is spaced over an extended period of time. When learning is spread over several sessions, knowledge acquisition and long-term retention are better than if sessions of the same material are delivered together [3].

Some limitations are that this study took place at a single institution and measured only feasibility, satisfaction, and self-reported knowledge. In addition, the activity is limited by the amount of content delivered. Although important topics related to COVID-19 were covered, it was not possible to distill all new, relevant information into 15 items. As the pandemic developed, two additional quizzes were created and distributed.

We have shown that virtual quiz-based microlearning is a viable model for the rapid dissemination of knowledge to large numbers of health professionals during the current pandemic. Given its success, this type of education should become a vital component of future continuing professional development. 


\section{Declarations}

Ethics Approval This study was reviewed by our institution's IRB (\#201384) and was deemed exempt. The quiz was written and published as part of the regular operations of the Center for Advanced Mobile Health Learning.

\section{Informed Consent NA}

Conflict of Interest The authors declare no competing interests.

\section{References}

1. Dhawan S. Online learning: a panacea in the time of COVID-19 crisis. J Educ Technol Syst. 2020;49(1):5-22. https://doi.org/10. $1177 / 0047239520934018$.
2. Larsen DP, Butler AC, Roediger HL. Test-enhanced learning in medical education. Med Educ. 2008;42(10):959-66.

3. Kerfoot BP, Brotschi E. Online spaced education to teach urology to medical students: a multi-institutional randomized trial. Am J Surg. 2009;197(1):89-95.

Publisher's Note Springer Nature remains neutral with regard to jurisdictional claims in published maps and institutional affiliations. 